\title{
ENSAIO DE CRÍTICA AUTOBIOGRÁFICA: TRAJETOS DE VIDA E DOCUMENTOS DE PERCURSO NOS PROCEDIMENTOS METODOLÓGICOS DE ESCRITA DE UM ROMANCE
}

\author{
AUTOBIOGRAPHICAL REVIEW ESSAY: LIFE PATHS AND TRAVEL \\ DOCUMENTS IN METHODOLOGICAL PROCEDURES OF A NOVEL \\ WRITING
}

Luciany APARECIDA ${ }^{1}$

\begin{abstract}
Resumo: Nesse texto apresento procedimentos metodológicos que venho realizando no processo de produção e escrita de um romance. Faço aqui um ensaio de crítica autobiográfica, pontuando esse conceito como aproximação e cruzamento entre campos da história e da criação literária. Os resultados da pesquisa que realizo para a produção do texto ficcional são lidos como documentos de percurso. São esses trajetos de vida ou micro-histórias de algumas mulheres que na sociedade colonial brasileira (séculos XVIII e XIX) foram comerciantes em trânsito de mercadorias e realizaram pontuais movimentos de liberdade (escrava/liberta; casada/separada; comerciante), destacando encruzilhadas entre essas trajetórias como pontos de apoio e resistência.
\end{abstract}

Palavras-chave: Crítica autobiográfica. Trajetos de vida. Documentos de percurso. Cartografias de mulheres. Brasil Colônia.

\begin{abstract}
This paper reports on methodological procedures that I have used during the writing process of a novel. It is presented as an autobiographical review essay whose concept is seen as an approach and intersection between History and Literary creation. The material used as a basis for fiction writing is read as travel documents. These are life paths or micro-stories of a few women who were merchants in transit of goods in the Brazilian colonial society (18th and 19th centuries). These women were responsible for punctual freedom movements in their context (slave/free; married/separated; merchant), highlighting the crossroads between these paths as points of support and resistance.
\end{abstract}

Keywords: Autobiographical review essay. Life paths. Travel documents. Women cartographies. Brazilian colonial period.

\section{Estrada}

A literatura brasileira contemporânea tem apresentado obras que propõem diferentes pontos e referências para pensar e ver o mundo, diversos modos de re/leituras dos gêneros literários, modelos de escrita que têm experimentado os gêneros a partir de tomadas mais

\footnotetext{
${ }^{1}$ Doutora em Letras pelo Programa de Pós-Graduação em Letras da Universidade Federal da Paraíba. Professora Substituta da Universidade da Integração Internacional da Lusofonia Afro-Brasileira - UNILAB. luciany.aaparecida@gmail.com
} 
amplas e que aproximam definições antes trazidas como marcas conceituais da diferença. Re/leituras essas que reelaboram diferenças desde os modos de apresentação estética do texto até o trabalho temático: são escritas em ações autobiográficas ${ }^{2}$. Essa tem sido uma prática realizada por escritoras e escritores que desejam inserir à tradição da literatura brasileira rasgos de suas existências.

No Brasil, cada vez mais, esses trabalhos em recortes de vida e/ou defensas de identidades tantas vezes sequestradas dos lugares nobres das letras clássicas têm sido apresentados por pequenas editoras que têm realizado um trabalho de autocuradoria. Ou seja, editoras que funcionam como coletivos, grupos de escritoras/escritores que juntos, associados, pensam seus livros em todas as etapas - da revisão do texto às escolhas gráficas de papel, de modelos do livro, distribuição e venda. Ações que possibilitam a existência de maior divulgação de livros de artistas que antes poderiam ficar reservadas a uma única edição da autora / do autor.

É importante destacar que o Brasil tem se movimentando tanto como um país múltiplo como lento no que se refere às reações institucionais de fuga aos modelos colonialistas. Quer dizer, mesmo com o crescente e abrangente número de publicações de novas escritoras contemporâneas / novos escritores contemporâneos não significa que esse mesmo movimento seja abarcado, considerado e / ou mesmo lido por instituições das letras que no Brasil sustentam as orientações de quem, por exemplo, pode ganhar ou não ganhar dinheiro com literatura.

Assim, no Brasil vemos a arte (nesse contexto, a literatura) ora como um campo fértil à resistência, ora um repetitivo reelaborar de opressões. Modos de opressão que registram como marca maior a fixação por estruturas padronizadas na colonialidade. Por exemplo, ainda é corriqueira a busca de escritores que se encaixam no padrão: homem, cis, branco, classe média/alta, hétero e do Sudeste (hoje região central do poder econômico do país).

A partir dessa perspectiva, a literatura brasileira contemporânea que apresenta uma escrita com práticas e/ou exercícios de autobiografia não escapa a essas tensões. Tanto para reagirem a elas como para reafirmá-las. As reações narram um campo positivo de novos mapas identitários apresentando como existência diferentes possibilidades de vida. Com louvor podemos buscar na literatura brasileira contemporânea (e encontrar) excelentes, e de variadas perspectivas, trabalhos de escritoras mulheres (cis e trans), negras, de periferias (geográficas ou

\footnotetext{
2 Exemplo disso é a obra do poeta Ricardo Aleixo. Por exemplo, o livro de poemas Modelos vivos. Sobre esse tema e autor ver a tese: APARECIDA, Luciany Alves Santos. Modelos vivos em uso: Poesia e performance de Ricardo Aleixo (em) um exercício crítico de literatura contemporânea. 2015. Tese (Doutorado em Letras) Programa de Pós-graduação em Letras. Universidade Federal da Paraíba, João Pessoa. p. 254 f. Disponível em: <https://repositorio.ufpb.br/jspui/handle/tede/8524>. Acesso em: 07 jul. 2019.
} 
financeiras), $\mathrm{LGBTQIA}+{ }^{3}$ que re-inscrevem a si na cena-mundo como corpos de presença. Modelos vivos que existem performando seus próprios desejos e sonhos. E nesse jogo de existir e resistir re-escrevendo a si produzem uma interferência que circuita do corpo que produz a letra ao corpo que lê. Escrita e leitura ganham, assim, na contemporaneidade uma potência de produção de circuitos geradores de vidas e irmandades ${ }^{4}$. Escritas de si que dançam e apoiam-se em movimentos de autodefesas.

Indispensável afirmar que a possibilidade de encontro dessas literaturas não significa suas hegemonias ou o aceite completo dessas produções. Os rastros estruturais dos costumes culturais (racismo, machismo e LGBTfobias) da herança colonial no Brasil são animais vivos, com nomes e sobrenomes, que se reproduzem sem parar nos lugares de poder da sociedade e que, assim, vão mantendo suas práticas danosas. Enferrujada, a engrenagem sistêmica da construção de referencial de escritas de si que a literatura brasileira produz, ainda, em muitos casos, mantém corpos de mulheres, negros e LGBTQIA+, quando visibilizados, presos a imagens fixas, unilaterais e pejorativas (de si).

Nessa perspectiva é necessário ler e escrever literatura como um ato estético-político de defesa da visibilidade de histórias de vida. Quando uma mulher teoriza seu trajeto de vida ela nunca está sozinha: ela sempre estará rastreando ancestralidades e sinalizando futuro. Assim, manifesto a partir de minha escrita (literária + acadêmica) desejos de interferir no mundo, cavando trincheiras para, quem sabe num dia futuro, estremecer paredes de segregação.

Nesse ensaio, como escritora contemporânea, apresento um pensamento teórico-crítico sobre procedimentos metodológicos que venho realizando para a criação literária de um romance. A história de duas mulheres, de diferentes origens, que no Brasil de finais do século XVIII e começo do século XIX se veem envolvidas num sentimento-romântico-amoroso. Apaixonadas e separadas por demarcações religiosas, morais, políticas e jurídicas daquele período, suas narrativas de vida dizem de tensões e existências que talvez apenas tomando como marco o texto histórico nunca pudéssemos considerar suas existências como reais.

\footnotetext{
3 São exemplos, os títulos publicados pela Padê Editorial em Brasília, pela Ogum's Toques Negros, Editora Organismo e a Pantim Edições em Salvador e pontualmente o trabalho de escritoras como Natália Borges Polesso (RS) e Louise Queiroz (BA). Ainda sobre esse assunto, ver a matéria: <https://www.nexojornal.com.br/expresso/2019/06/30/O-r\%C3\%B3tulo-literatura-1\%C3\%A9sbica-impulsionaou-limita-as-obras>. Acesso em: 07 jul. 2019.

${ }^{4}$ Nesse contexto, podemos pensar pontualmente nos saraus que têm sido no Brasil afora e adentro cenas artísticas de realização da existência e desenvolvimento de identidades de várias e de vários jovens. Identidades de raça, classe, gênero, orientações sexuais que excluídas das cenas padrões das letras clássicas brasileiras, se organizam e ganham força e corpo nas ruas. São exemplos, o Sarau da Onça em Salvador, Sarau Debaixo em Aracaju, Sarau Cooperifa em São Paulo, entre tantos outros.
} 
A busca por sinais das histórias de vida dessas mulheres como documentos de percurso ao fim e ao longo do processo produzirá mapeamentos metodológicos dos passos que trilharei para a escrita do romance. Fazendo assim do documento de percurso um material vivo e dinâmico que interfere nos procedimentos de escrita gerando novas possibilidades ao trajeto da narrativa.

Nesse texto, documentos de percurso serão: cartas de alforria, fotografias, diários, processos-crimes, testamentos, bibliografias de história especializadas no assunto. Textos vivos sob os quais construirei rasuras e/ou apagamentos (palimpsestos) que darão por si novos trajetos. Os mapas metodológicos dirão da biografia das mulheres e de uma autobiografia do meu caminhar para a elaboração do enredo.

Desse modo, o texto literário, em conversa com a história e a estética, cria realidades possíveis. Organizo esse ensaio como movimentos que disparam um circuito. Apresento quatro movimentos: Movimento 1) mulheres de caminho/ um conceito; Movimento 2) meu corpo nos caminhos das fontes; Movimento 3) biografias históricas; Movimento 4) conclusões de linguagem e um circuito - escritas de si.

É a partir desses pensamentos e elaborações teórico-críticas e considerando a autobiografia como "campo do conhecimento histórico", "campo da ação" e "campo da criação artística"5 que elaboro esse mapa-conceitual e crítico de movimentos e ligação de circuito - a escrita. A escrita desdobrada: a) na elaboração crítico-autobiográfica desse ensaio e b) nos rastros da escrita do (planejado) romance.

Então, esse texto-mapa surge do campo de ação de escrever um romance que terá como tema mulheres. Nessa ação de escrita, como disse anteriormente, acionarei ancestralidades, sinalizando mulheres futuras. Para a realização estética do campo da ação, acionei os campos do conhecimento histórico e da criação artística.

É necessário ponderar que esse ensaio se organizará em minha trajetória de vida como um documento de percurso de minhas próprias investigações experimentais para a escrita literária. Junto a isso, correndo em trânsito a esta ação de autorreflexão teórica da prática de

5 Philippe Lejeune no livro Pacto autobiográfico de Rousseau à internet, no capítulo "Autobiografia e ficção", diz: "A autobiografia se insere no campo do conhecimento histórico (desejo de saber e compreender) e no campo da ação (promessa de oferecer essa verdade aos outros), tanto quanto no campo da criação artística" (LEJEUNE, 2008 , p. 104). Dessa citação do autor de pensar a autobiografia a partir desses três campos, os tomo como ponto de ordem metodológica para iniciar a produção organizacional desse ensaio. É pensando a escrita literária como uma ação que envolve a história e criação artística que elaborarei aqui metodologicamente os passos desse ensaio-crítico-autobiográfico. LEJEUNE, Philippe. Pacto autobiográfico de Rousseau à internet. Trad. Jovita Maria Gerheim Noronha e Maria Inês Coimbra Guedes. Belo Horizonte: Editora UFMG, 2008. p. 103 - 109. 
escrever um romance, falo também do trajeto de vida de mulheres que viveram no Brasil dos séculos XVIII e XIX e de como suas existências se conectam à possibilidade de vida de mulheres para além de seu tempo.

Desse modo, nesse ensaio, também, a ideia de documentos de percurso será um desdobramento entre as fontes históricas com as quais trabalharei e o próprio ato em si de trabalhar com essas fontes. Quer dizer, esse ensaio é um documento de percurso nos caminhos que estou trilhando para a elaboração do romance.

Assim, a escrita literária e a escrita acadêmica se desdobram em efeitos de autometamorfose e autorreferência. Efeitos metodológicos que provocam uma escrita de si - no sentido de que estou escrevendo teoria e crítica sobre atos de produção de narrativa que estou realizando. Nesse contexto, não estou produzindo análise teórica sobre um texto literário, mas com um texto literário. Movimentos que geram sem parar construções narrativas minhas, delas, dessas palavras e de outrem, ampliando, desse modo, formas de leitura e escrita do nosso tempo e de nossa produção de arte. Ações que se conectam com contemporâneos modos de pensar as teorias sobre auto-publicação e autobiografias. Aproximando essas ações precisamos criar novos conceitos e/ou alargar conceitos sobre a área de gêneros literários.

\section{Movimento 1 - mulheres de caminho/ um conceito}

Maria Anna Rita de Meneses, Bárbara Gomes de Abreu e Lima e Joana da Silva Machada são mulheres que viveram no Brasil no período colonial (séculos XVIII e XIX). Tenho buscado traçar a história de vida dessas mulheres a partir de pesquisas bibliográficas e em fontes primárias. Quero a partir das pesquisas de produção do livro realizar uma cartografia de mulheres de caminho ${ }^{6}$.

Mulheres de caminho é expressão que faz referência às mulheres que, no século XVIII, trabalhavam em trânsito, no comércio de mercadorias. Trabalho comumente realizado por

\footnotetext{
${ }^{6} \mathrm{Li}$ a primeira vez a expressão "mulheres de caminho" na tese "Homens de caminho: trânsitos, comércio e cores nos sertões da América portuguesa - século XVIII" de Isnara Pereira Ivo (PPGH/UFMG, 2009). Na nota de rodapé 783 a historiadora explica que faz usa da expressão “"mulheres de caminho' como derivação da expressão empregada na documentação para os homens envolvidos nas atividades comerciais nos sertões, embora 'homens de caminho' fosse expressão empregada para todo o conjunto de transeuntes e para todos os envolvidos na arrematação de contratos, nas declarações de passagens de registros fiscais e nas ações descaminhos" (IVO, 2009, p. 296).
} 
homens e, por isso, a expressão mais comum é homens de caminho. No entanto, registros comprovam que essas atividades comerciais também foram desempenhadas por mulheres ${ }^{7}$.

Nesse ensaio ao escrever "mulheres de caminho" pensarei numa investigação de mulheres que nos séculos XVIII e XIX realizaram essas atividades de trânsitos comerciais e a utilizarei também para conceituar mulheres que, mesmo em outras práticas que não no comércio de mercadorias, tenham exercido micro-trânsitos de liberdade.

Acertemos que, nesse texto, mulher de caminho será referência ao perfil que tenha apresentado em sua trajetória movimentos de acessos e/ou mobilidades contra a sociedade escravista e patriarcal de então. A existência delas, os sinais de suas trajetórias, são destaques que me interessam como argumentação de uma cartografia feminina de resistência no Brasil colônia.

Nesses termos, trarei aqui alguns resultados da pesquisa que venho realizando ${ }^{8}$ sobre mulheres africanas, crioulas $^{9}$, forras, libertas ${ }^{10}$, brancas-casadas e brancas-largadas ${ }^{11}$, na sociedade colonial brasileira, nos séculos XVIII e XIX. Pensando relações e tensões de gênero, raça e classe ${ }^{12}$ que os encontros entre essas mulheres podem ter desencadeado.

Cartografar a trajetória dessas vidas é interessante no sentido de montar uma base de dados para que possamos ter acesso aos perfis dessas "mulheres de caminho". Essa base biográfica deve ser tomada como ponto múltiplo de tensão para discussões teóricas que tensionem as dualidades e/ou separações estáticas que fixam com distanciamento e rigidez as disciplinas história e literatura e/ou os gêneros romance biográfico e romance "clássico".

\footnotetext{
${ }^{7}$ Encontrei referências sobre essas mulheres em: PAIVA, Eduardo França. Escravidão e universo cultural na colônia, Minas gerais, 1716-1789. Belo Horizonte: Editora da UFMG, 2001.

${ }^{8}$ Como pesquisadora do grupo, Cartografias das culturas populares, na linha de pesquisa, Trajetos de vida de mulheres (cis e/ou trans), documentos de percurso, experimentações gráficas.

${ }^{9}$ No período colonial, referência às mulheres nascidas no Brasil filhas de africanas.

${ }^{10}$ Forras e libertas são referências a mulheres (africanas e/ou crioulas) que viviam em condição de escravizadas e que compraram ou adquiriram suas cartas de alforria.

${ }^{11}$ Destaco que faço uso das expressões africanas, crioulas, forras, libertas, branca-casadas e branca-largadas para manter coerência e referência ao período histórico (Brasil dos séculos XVIII e XIX). Saliento que a expressão branca-largada pode ao longo do texto aparecer na variação branca-separada. No período de finais do século XVIII e começo do XIX no Brasil não existia como forma legal a possibilidade do divórcio para a mulher. Portanto, nos documentos aparece a referência mulher largada. No entanto, mais à frente neste ensaio, trabalharei com um documento (referenciado nas pesquisas do historiador João José Reis) que conta de um caso de uma mulher que solicitou judicialmente sua separação. Esse caso, desse modo, justifica porque neste ensaio escrevo mulher brancalargada com a variação mulher branca-separada. Destaco ainda que é uma marca que faço para esse texto a forma mulher branca-casada e/ou largada-separada, pois é necessário à pesquisa que realizo para o romance a pontuação da cor das referidas mulheres.

12 Tendo como referência o livro Mulheres, raça e classe de Angela Davis. DAVIS, Angela. Mulheres, raça e classe. Trad. Heci Regina Candiani. São Paulo: Boitempo, 2016.
} 
Nesse exercício de pensamento considero trajetos de vida e documentos de percurso como encruzilhadas com estradas abertas para encontros mais saudáveis entre distintos eixos de pensamento.

\section{Movimento 2 - meu corpo nos caminhos das fontes}

Pensar sobre trajetos de mulheres na sociedade brasileira colonial é ação necessária para entendermos as relações entre mulheres na sociedade brasileira contemporânea ${ }^{13}$. E em nosso tempo político presente ${ }^{14}$ pensar o feminino ${ }^{15}$ e suas complexidades tornou-se vital ${ }^{16}$. É ação de defesa da vida. É acionamento de segurança física e sanidade mental.

Assim iniciei uma investigação de micro-histórias de mulheres na sociedade colonial nos séculos XVIII e XIX, nas regiões do Termo de Cachoeira, na Cidade da Bahia, na Vila de São João Del Rei/ Capitania das Minas Gerais e na Vila do Santo Antônio do Recife, a partir de fontes como processos crimes, testamentos, cartas de alforrias, certidão de batismo e de casamento e referências bibliográficas específicas.

Tenho feito o levantamento desses documentos em leituras historiográficas; em pesquisas no Arquivo Público da Bahia (na cidade de Salvador) e no Arquivo Público de Cachoeira (cidade no recôncavo da Bahia); em viagens de pesquisa à Estrada Real (região do ciclo do ouro no estado de Minas Gerais, especificamente a Vila de Biribiri, Diamantina) e à Estrada dos Escravos (também Diamantina/MG); em cúrias e igrejas, como a Capela do Corpo Santo (Salvador/BA); em museus, como o Museu de Arte Sacra da Bahia e Museu Henriqueta

\footnotetext{
13 Os livros Sobre o autoritarismo brasileiro e $O$ espetáculo das raças, da antropóloga e historiadora Lilia Moritz Schwarcz são importantes referências para pensarmos trajetos das opressões no Brasil - do período colônia à contemporaneidade. SCHWARCZ, Lilia Moritz. Sobre o autoritarismo brasileiro. São Paulo: Companhia das Letras, 2019. SCHWARCZ, Lilia Moritz. O espetáculo das raças: cientistas, instituições e questão racial no Brasil 1870-1930. São Paulo: Companhia das Letras, 1993.

${ }^{14}$ Brasil pós-golpe que destituiu do cargo a presidenta eleita Dilma Rousseff em 2016 e pós-processos eleitorais de 2018.

${ }^{15}$ Feminino como todo o campo de performatividade do que se lê como mulher. Não no sentido machista e heteronormativo compulsório do termo que significa mulher em ação de agradar "homens". Mas feminino como ação performativa-política de ampliação dos alcances de resistência e contraposição do ser mulher - em destaque que mulher não em reprodução da binariedade (homem x mulher) mas nas diferentes possibilidades (cis e trans) de performar esse feminino.

16 Segundo a reportagem Mais de 200 feminicídios ocorreram no país em 2019, segundo pesquisador do jornal "O Globo", publicada em 07 de março de 2019 no Brasil (de janeiro até a data de fechamento da referida matéria), uma mulher foi assassinada a cada quatro horas e trinta e um minutos. Disponível em: $<$ https://oglobo.globo.com/sociedade/mais-de-200-feminicidios-ocorreram-no-pais-em-2019-segundopesquisador-23505351>. Acesso em: 07 jul. 2019.
} 
Catharino e Instituto Feminino da Bahia (em Salvador) e à antiga casa de férias do Instituto Feminino da Bahia, que hoje é a residência do Instituto Sacatar, na Ilha de Itaparica/BA ${ }^{17}$.

Com essas fontes, venho elaborando um método de leitura a partir das chaves: gênero, raça e classe. Especificamente cada uma dessas chaves de entrada se desdobrará em duplas questões. A partir das leituras de gênero penso lugares sociais da mulher (mulheres africanas, crioulas, forras, libertas, brancas-casadas e brancas-largadas) nessa sociedade, colocando em questão possibilidades de lugares de relações afetivas entre elas nesse contexto; a partir das leituras de raça, penso essa conjuntura em diferenças de cor (mulher negra e mulher branca) e de fé (mulher católica e mulher jeje); da chave de classe, com ressalva, para não incorrer em anacronismos conceituais, penso movimentações sociais dessas mulheres, dando mais atenção a relações entre mulher forra/liberta e mulher-branca (casada e/ou separada) possuidora de algum lugar de poder social e mando.

A elaboração desses procedimentos metodológicos de registro e catalogação dos dados que vou levantando desse período apontam de modo mais complexo para os possíveis modos de relações dessas mulheres, o que gera uma cartografia ampliada e com maior alcance de identificação.

\section{Movimento 3 - biografias históricas}

É a partir desse lugar de perigo, como parece ser a configuração antropológica do tempo presente, que aciono enredos do passado, para que possamos acionar em nós esperanças para o tempo de agora. Pensar a mulher negra (africana, crioula, forra, liberta) na sociedade colonial (séculos XVIII e XIX) é acionar estratégias de resistência. Metodologias de pesquisa e escrita que têm tradição na historiografia brasileira se pensarmos, por exemplo, os trabalhos de João José Reis (Domingos Sodré: um sacerdote africano, 2008), Isabel Reis (A família negra no tempo da escravidão: Bahia 1850-1888, 2007), Walter Fraga (Encruzilhadas da Liberdade: histórias de escravos e libertos na Bahia, 1870-1910, 2006) e Clíssio Santana ("Ele queria viver como se fosse homem livre": escravidão e liberdade no Termo de Cachoeira (1850-1888), 2014).

\footnotetext{
${ }^{17}$ Tenho desenvolvido esta pesquisa, sem financiamento, desde 2017. Avalio aqui que se tivesse apoio financeiro, o projeto de pesquisa e escrita do romance estaria deveras mais encaminhado.
} 
Nesse texto sigo a rota de trânsitos que nos provocam no tempo presente: seja na escolha da temática, busca de mulheres em movimento de próprios caminhos, seja na perspectiva de escrita da história.

A escrita da história e a escolha do tipo de leitura que se fará do passado/ escolha teóricometodológica dos caminhos a seguir nas leituras históricas de vestígios são tomadas aqui como a tessitura de encontros que poderiam ter existido. Os perfis das mulheres de caminho podem nunca ter se encontrado, mas poderiam. Uma pesquisa histórica em ação com desejos de uma construção narrativa ficcional pode encontrar possibilidades dessas tensões, desses afetos, as possibilidades de elas terem dado sentido umas às vidas das outras. E para isso um trabalho de pesquisar/investigar trajetórias fronteiriças de/entre mulheres: africanas, crioulas, libertas, forras, brancas-casadas e brancas-largadas e colocar estas em encruzilhadas - sendo que é aditável que venha a ser na encruzilhada que elas poderão tornar possível um presente encontro.

Nas ideias do filósofo Giorgio Agamben (2009), sombrear as luzes de nosso tempo é ação para um fazer/ver contemporâneo. Diz o autor "pode dizer-se contemporâneo apenas quem não se deixa cegar pelas luzes do século e consegue entrever nessas a parte da sombra, a sua íntima obscuridade" (AGAMBEN, 2009, p. 63-64). Quer dizer, num dia de sol forte e cabeça descoberta, ao se receber um antigo bilhete escrito a lápis numa folha de papel branco, precisaremos, para acionar a leitura daquela mensagem, sombrear o papel para que nossa leitura não fique cega com o facho de luz de nosso próprio tempo. Ou, de modo específico, nas palavras de João Reis e Elciene Azevedo:

[...] por "sombras da escravidão" entendam-se fenômenos e processos históricos que da escravidão se projetam no tempo, para além da Abolição, e/ou se articulam com o fenômeno axial que é a instituição do cativeiro enquanto existiu. Assim, histórias de liberdade vivenciadas no tempo em que o cativeiro vigeu formalmente pertencem ao território das sombras (REIS; AZEVEDO, 2012, p. 8-9).

Nessa perspectiva saber (investigar) processos históricos que são dos territórios das sombras do período da escravidão nos faz melhor enxergar aquele tempo e o nosso. Nesse ponto apresento a essa argumentação metodológica a africana Joana da Silva Machada - nome de batismo recebido nas terras brasileiras -, para começarmos a pensar a ideia da denominação, uma mulher de caminho, a partir de micro-histórias.

Joana da Silva Machada era conhecida como Joana Mina, africana sequestrada da Costa do Benin para o Brasil no período da primeira metade do século XVIII. Joana registrou seu 
testamento em 1745 na Vila do Santo Antônio do Recife ${ }^{18}$ e faleceu em 1847 no "Arraial dos Carijós, próximo à Vila de São João del Rei, na capitania das Minas Gerais" (PAIVA, 2012, p. 12). O porquê do deslocamento da africana da Vila do São João do Recife para a capitania das Minas Gerais não se pode afirmar com exatidão, o historiador Eduardo França Paiva, supõe que:

\begin{abstract}
A motivação parece que estava ligada às motivações econômicas desenvolvidas pela forra, as quais aparecem indicadas em seu testamento e envolviam o comércio de tecidos, roupas e outros objetos. Joana engrossava, muito provavelmente, o grupo de pessoas que transitava entre essas regiões trazendo e levando mercadorias para serem negociadas $[\ldots]$ Nossa personagem deve ter sido mulher decidida, que transitava por caminhos marcadamente masculinos, nos quais obteve êxito, se considerarmos sua fortuna declarada em testamento e inventariada após sua morte (PAIVA, 2012, p. 12, grifo meu).
\end{abstract}

Trechos do testamento ${ }^{19}$ de Joana Mina revelam uma forte ligação que esta pode ter tido com a Cidade da Bahia, visto que, como também destaca Paiva (2012), ela deixa encomendadas várias capelas de missas por sua alma e uma lista de testamenteiros em sua maioria da Cidade da Bahia. Conseguindo o acesso a esse testamento e em uso da metodologia de ligações nominativas, pretendo estabelecer um cruzamento de séries documentais diferentes a partir das conexões estabelecidas pelos nomes das pessoas para, por exemplo, buscar em arquivos da Bahia, em documentos de confrarias religiosas, os nomes que ela deixa como testamenteiros de seus bens e quem sabe buscar passos dessa mulher de caminho na Bahia.

Outra mulher de caminho foi Bárbara Gomes de Abreu e Lima, filha legítima dos africanos Antonio Benguela e Maria Gomes do Gentio da Mina. Era crioula, nascida na região de Sergipe Del Rei, alforriada na região da Capitania de Minas Gerais. Em 1735 ditou seu testamento e revela uma pomposa fortuna. Bárbara possuía uma "morada de casas" em Sabará, "uma das vilas mais poderosas de Minas" (PAIVA, 2012, p. 16). Segundo Eduardo França Paiva a partir dos bens ditados no testamento de Bárbara é possível supor que "sua fonte de renda estava ligada ao comércio entre Bahia e a comarca do Rio das Velhas, feito ao longo do

\footnotetext{
${ }^{18}$ Como indica Eduardo França Paiva em: PAIVA, Eduardo França. Mulheres de diversas "qualidades" e seus testamentos na colonial, escravista e mestiça capitania das Minas Gerais. In: XAVIER, Giovana; FARIAS, Juliana Barreto; GOMES, Flávio (orgs.) Mulheres Negras no Brasil Escravista e do Pós-Emancipação. São Paulo: Selo Negro, 2012. p. 11-23

19 Apresentados por Paiva no artigo: PAIVA, Eduardo França. Mulheres de diversas "qualidades" e seus testamentos na colonial, escravista e mestiça capitania das Minas Gerais. In: XAVIER, Giovana; FARIAS, Juliana Barreto; GOMES, Flávio (orgs.) Mulheres Negras no Brasil Escravista e do Pós-Emancipação. São Paulo: Selo Negro, 2012. p. 11-23.
} 
“caminho dos currais"” (PAIVA, 2012, p. 17). Os trajetos de vida de Joana e de Bárbara, mesmo que deslocados um do outro temporalmente, conectam-se: há ligação de trajetos, uma na possibilidade de existência da outra.

Maria Anna Rita de Meneses, mulher branca de família escravista baiana do começo do século XIX - "fillha do capitão-mor de Cachoeira, Antonio Brandão Pereira Marinho Falcão" (REIS, 2008, p. 72) -, é perfil que pretendemos investigar e entender como mulher de caminho - no sentido amplo de mulher que ocupou um lugar de mando, de coragem ou mesmo, nas inspiradoras palavras de Reis, mulher que "não tinha um espírito conformista".

Dona Maria Rita teve uma vida conjugal conturbada, já que não tinha um espírito conformista. Casara-se ainda menina, de doze ou treze anos, com seu primo e tio, coronel Gonçalo Marinho Falcão, o que não era incomum, nem na idade, nem no grau de endogamia familiar. Por estas ou outras razões, que incluíam o caráter rebelde da jovem, o casamento não vingou. Maria Rita moveria contra o marido uma ação de divórcio (REIS, 2008, p. 72-73, grifo meu).

Cronologicamente a história dessas três mulheres não se cruza, conexões podem ser estabelecidas a partir de características do tempo delas, os espaços que podem ter percorrido, situações de força e enfrentamentos que podem, respeitadas as complexas e específicas diferenças existentes em cada perfil, ter enfrentado.

No entanto, o que mais me interessa é elas terem existido e a possibilidade de interconexão entre suas trajetórias e o mundo de possibilidades individuais e coletivas que elas nos abrem. Investigar, pensar, religar esses trajetos que são "sombras da escravidão"20 é possível porque essas mulheres de caminho foram, em seus tempos, contemporâneas. Parafraseando Agamben ${ }^{21}$, elas foram corajosas a ponto de terem sido pontuais a compromissos aos quais puderam apenas faltar.

Para Agamben, o contemporâneo é um corajoso que enfrenta seu tempo. Essas mulheres fizeram de seus caminhos corpos de presença ${ }^{22}$ no mundo que o passar do tempo não apaga. Ao contrário, acende e ascende. Nas palavras do autor, "é como se aquela invisível luz, que é o

\footnotetext{
20 (REIS; AZEVEDO, 2012, p. 8).

${ }^{21}$ Conforme a tradução, o autor diz: "ser pontual num compromisso ao qual se pode apenas faltar". AGAMBEN, Giorgio. O que é o contemporâneo? E outros ensaios. Trad. Vinícius Nicastro Honesko. Chapecó: Argos, 2009.

${ }^{22}$ Corpos de presença como um objeto-texto que como produção de presença, como rasgo ou risco num instante de tempo presente interfere e modifica a vida de quem se coloca em frequência com essas existências. Escrevo produção de presença em referência ao livro: GUMBRECHT, Hans Ulrich. Produção de presença: o que o sentido não consegue transmitir. Trad. Ana Isabel Soares. Rio de Janeiro: Contraponto: Ed. PUC-Rio, 2010. Mais sobre esse tema elaborei e escrevi na tese: APARECIDA, Luciany Alves Santos. Modelos vivos em uso: Poesia e performance de Ricardo Aleixo (em) um exercício crítico de literatura contemporânea. 2015. Tese (Doutorado em Letras) - Programa de Pós-graduação em Letras. Universidade Federal da Paraíba, João Pessoa. p. 254 f. Disponível em: 〈https://repositorio.ufpb.br/jspui/handle/tede/8524>. Acesso em: 07 jul. 2019.
} 
escuro do presente, projetasse a sua sombra sobre o passado, e este, tocado por esse facho de sombra, adquirisse a capacidade de responder às trevas do agora" (AGAMBEN, 2009, p. 74).

\section{Movimento 4 - conclusões de linguagem}

Do campo da história, trago as grafias dessas vidas e vou assim formando os traços das personagens que comporão o meu romance. Pondero que escrever uma narrativa seja tracejar realidades numa ação de mimese não plana, não linear, mas volumosa. Estrada aberta para a vida e não fechada na dualidade (realidade x ficção).

O campo da criação literária é vasto e farto de possibilidades e a partir dele penso o registro metodológico de documentos de percurso como mapas de exposição de linguagens epistêmicas. Cartografar essas mulheres de caminho é a criação de um chão teórico que nos possibilita pensar esses diferentes corpos de presença em um sentido distendido de tempo.

Os frutos estranhos ${ }^{23}$ que brotam desse chão teórico alforriam a história e a literatura de campos dissociados. Aproximados, esses campos podem apresentar produções mais saudáveis.

Nesse jogo vence a linguagem em seus efeitos de auto-metamorfose e autorreferência. A linguagem em campos de produção de múltiplos sentidos de si.

\section{Circuito - escritas de si}

A cartografia das mulheres de caminho gera os frutos estranhos como resultados das aproximações dos campos. Essa ação de jogo da história com a criação literária liga o circuito e o texto nunca termina. Assim, esse ensaio, em si só, não se completa. Ele risca aqui possibilidades sobre metodologias de escrita que estou elaborando e que quiçá concluirei. No entanto, ligado, ele permite nossa existência no aqui-agora do presente dessa leitura.

Nesse caminho, ler pode ser acionar existências. Se leio e me reconheço e/ ou me identifico naquela história, posso entender melhor minhas necessidades e elaborar saudáveis e multiplicadas performances sobre/para meu corpo. Infelizmente, a partir de suas marcações históricas, o Brasil é um país que foi e segue se configurando em circuitos de violência e não

23 Frutos estranhos é referência ao poema de Lívia Natália, que faz referência à música Strange fruit de Billie Holiday. A música da cantora afro-americana fala de movimentos racistas e antirracistas dos Estados Unidos da América e formas de resistências negras. A poeta, referenciando a música, diz nos primeiros versos "No tempo possível,/talvez na chegada da noite enlutada/os frutos estranhos serão colhidos" (NATÁLIA, 2017, p. 65). NATÁLIA, Lívia. Sobejos do mar. Salvador: Edições Caramurê, 2017. O poema pode ser lido na íntegra no endereço: 〈https://www.germinaliteratura.com.br/2019/livia_natalia.htm〉. Acesso em: 07 jul. 2019. 
de leitura. Presentemente, temos acompanhado em jornais impressos e programas de TV constantes ações políticas que têm causado um desmonte das até então frágeis estruturas educacionais do país. Espaços que podem e, em alguma medida, oferecem resguardo às posições estéticas de defesa de nossas identidades numa perspectiva mais ampla.

Se a educação é atingida, a leitura é consequentemente violentada. Em ambientes de opressão, a leitura possibilita a ampliação de nossos si(s). A descoberta ou reconhecimento de nossas identidades pode estar, tantas vezes, associada à leitura de um poema, um romance, um conto ou uma biografia. E nesse reconhecimento é como se o nosso si, ali refletido, e/ ou reconhecido, visse a si ali duplicado e não mais sozinho.

Num jogo de irmandade, após um reconhecimento, seguimos para nossas trajetórias de vida mais amparadas e mesmo confortadas por aquele rastro biográfico - que mesmo não sendo nosso, nos possibilitou existência. O passo adiante dessa identificação é a caminhada em par, é a elaboração de desejos, a permissão ao sonho e esperanças por melhores dias.

Nessa dança, ler é sonhar, ler é desejar, ler é ter esperanças, ler é oferecer descansos à solidão. A leitura como circuito da escrita de si ativa novas performances de si. Reconectando sem parar a ligação da escrita - com a leitura. Ação de escrever, ação de criar leituras possíveis e variadas sobre si no mundo.

Observamos até aqui como a criação literária de forma alguma pode continuar sendo lida como um campo entrincheirado da história ou vice-versa. A autobiografia pode e deve ser exercitada teórica e criticamente como ponte que positivamente conecta trajetos diferentes oferecendo aos estudos da literatura novos caminhos de vida.

Afirmo que elaboro enredo sobre mulheres de caminho para multiplicar minha própria existência. Escrevo ensaio crítico acadêmico com os documentos de percurso que vou levantando na prática da escrita criativa para multiplicar minha própria literatura.

Com o circuito ligado, lemos infinitamente escritas de si. Elaboram-se a partir desse jogo conceitual autobiografias, metodologias de pesquisa e escrita. Estreitamentos, estrangeiramentos, que mais que findar e/ ou derrubar campos em relação ao outro ampliam novas existências - quando não sustentam distinções.

Nesse jogo do complexo, o risco de novidade parece residir na aproximação que podemos estabelecer entre diferentes tempos e diferentes caminhos. Mulheres de caminho que contemporâneas de seu tempo chegam até nós com pontualidade e firmeza fazendo refletir em nós alertas do que podemos ainda performar.

Um circuito de escrita de si não deve ser desligado. 


\section{Referências}

AGAMBEN, Giorgio. O que é o contemporâneo? E outros ensaios. Trad. Vinícius Nicastro Honesko. Chapecó: Argos, 2009.

APARECIDA, Luciany Alves Santos. Modelos vivos em uso: Poesia e performance de Ricardo Aleixo (em) um exercício crítico de literatura contemporânea. 2015. Tese (Doutorado em Letras) - Programa de Pós-graduação em Letras. Universidade Federal da Paraíba, João Pessoa. p. $254 \mathrm{f}$.

DAVIS, Angela. Mulheres, raça e classe. Trad. Heci Regina Candiani. São Paulo: Boitempo, 2016.

FRAGA FILHO, Walter. Encruzilhadas da Liberdade: histórias de escravos e libertos na Bahia, 1870-1910. São Paulo: Editora da Unicamp, 2006.

GUMBRECHT, Hans Ulrich. Produção de presença: o que o sentido não consegue transmitir. Trad. Ana Isabel Soares. Rio de Janeiro: Contraponto: Ed. PUC-Rio, 2010.

IVO, Isnara Pereira. Homens de caminhos: trânsitos, comércio e cores nos sertões da América portuguesa - século XVIII. 2009. Tese (doutorado) - Programa de Pós-Graduação em História/UFMG, Belo Horizonte, MG.

LEJEUNE, Philippe. Pactoautobiográfico de Rousseau à internet. Trad. Jovita Maria Gerheim Noronha e Maria Inês Coimbra Guedes. Belo Horizonte: Editora UFMG, 2008. p. 103 a 109.

PAIVA, Eduardo França. Mulheres de diversas "qualidades" e seus testamentos na colonial, escravista e mestiça capitania das Minas Gerais. In: XAVIER, Giovana; FARIAS, Juliana Barreto; GOMES, Flávio (orgs.). Mulheres Negras no Brasil Escravista e do PósEmancipação. São Paulo: Selo Negro, 2012. p. 11-23.

PAIVA, Eduardo França. Escravidão e universo cultural na colônia, Minas gerais, 17161789. Belo Horizonte: Editora da UFMG, 2001.

PAIVA, Eduardo França. Escravos e libertos nas Minas Gerais do século XVIII: estratégias de resistência através dos testamentos. 3ed. São Paulo: Annablume; Belo Horizonte: PPGH-UFMG, 2009.

REIS, Isabel Cristina Ferreira. A família negra no tempo da escravidão: Bahia 1850-1888. Tese (Doutorado em História) - Departamento de História do Instituto de Filosofia e Ciências Humanas/Universidade de Campinas, Campinas, 2007.

REIS, João José; AZEVEDO, Elciene (Orgs.). Escravidão e suas sombras. Salvador: EDUFBA, 2012.

REIS, João José. Raimundo Sodré: um sacerdote africano: escravidão, liberdade e candomblé na Bahia do século XIX. São Paulo: Companhia das Letras, 2008. 
SANTANA, Clíssio Santos. "Ele queria viver como se fosse homem livre": escravidão e liberdade no Termo de Cachoeira (1850-1888). Dissertação, Programa de Pós-Graduação em História Social, Universidade Federal da Bahia, 2014, p. 177.

NATÁLIA, Lívia. Sobejos do mar. Salvador: Edições Caramurê, 2017.

XAVIER, Giovana; FARIAS, Juliana Barreto; GOMES, Flávio (Orgs.) Mulheres Negras no Brasil Escravista e do Pós-Emancipação. São Paulo: Selo Negro, 2012.

Recebido em: 07/07/2019

Aceito para publicação em: 07/11/2019 